\section{Entrevista: Izabel dos Santos}

Interview: Izabel dos Santos
Resumo Izabel dos Santos tem participado, ao longo de sua vida, de inúmeros projetos e programas de formação dos profissionais de saúde, dentre os quais podem-se destacar o Projeto Escola, o Projeto Larga Escala, e o Projeto de Profissionalização dos Trabalhadores da Área de Enfermagem (Profae). Está na origem de todos esses projetos e programas a contribuição de Izabel dos Santos para a construção de uma vontade política para a implantação de políticas públicas de formação do profissional de saúde, especialmente o de nível médio. Nesta entrevista, Izabel dos Santos, além de resgatar dimensões dos projetos mencionados, discute a articulação entre teoria e prática, a riqueza do trabalho, a regulação estatal da educação profissional em saúde e a educação a distância.
Abstract The history of Izabel dos Santos' life is inextricably intertwined with the history of the political struggle for the professional training of health workers. Throughout her life she took part in a large number of projects and programmes aiming at this type of training, including, among others, the Project Larga Escala, the Project Escola and the Project for the Professional Training of Workers in the Area of Nursing (PROFAE). As one of the co-founders of all these projects and programmes she fought for the development of a political will to create and implement public policies oriented to the training of health professionals, particularly those at the secondary level. In this interview, besides retracing some of the dimensions of the abovementioned projects, Ms. dos Santos discusses the articulation between theory and practice, the value of work, the State's regulation of professional education in health and extra-mural education. 
Quando e como você passou a se interessar por formular propostas para a Educação Profissional em Saúde?

Ao organizar serviços, o treinamento e a capacitação estavam contidos e era muito claro que havia faltas, lacunas, quase nenhuma experiência de educação em serviços, a não ser os treinamentos. No começo, não fazia diferença entre treinar e formar. Assim, deu uma luz e eu descobri que era preciso trabalhar com essa formação. Fui descobrindo coisas e relacionando-as, com o tempo. Por exemplo, hoje a gente diz que a formação faz inclusão social, promove cidadania etc. Eu não tinha isso claro e pronto de imediato, quando comecei. Acho até que, com as Conferências, o crescimento do debate foi contribuindo para promover maior articulação dos campos. Digo, a associação entre cidadania, saúde e formação. Olha, o que eu estou querendo dizer é que eu não concebi a priori um método, um conceito e que tinha por trás tal ou qual linha teórica. Fui fazendo e descobrindo. Aprendi fazendo. Quando comecei, não tinha claro que a formação era um selo de liberdade!!! Mas o que me mobilizou mesmo foi poder ajudar as pessoas que trabalhavam nos serviços, pessoas que estavam lá e ninguém valorizava, sequer enxergavam. Eram os invisíveis. Com o passar do tempo, pude perceber isso e ir criando um pensamento a respeito. Era preciso que a formação permitisse às pessoas ir além.

Naquela ocasião, qual causa impedia que os serviços dispusessem de processos de formação adequados ou de trabalhadores preparados?

O Sistema de Saúde! O setorial se omitia e a educação profissional era discutida por outros, como o MEC e outros. Isto levava a propostas desvinculadas da prática real, o que é inconcebível para mim. Por outro lado, no setor saúde, a prática comum era dos treinamentos utilitários e aligeirados. A formação profissional não era tema. Mas acho que o domínio específico quem tem que dar é o setorial, não é o MEC que vai conseguir pensar tudo isso. Consegui observar e fui até visitar e pude constatar que, em outros países na América Latina, era o Ministério da Saúde ou do Trabalho que davam as diretrizes para esse tipo de formação. Em Cuba não, era o MEC, mas a situação também é muito distinta com aquela rede de Politécnicos. Com as AIS [Ações Integradas de Saúde], a Reforma vai se instalando e a discussão vai tomando outra conotação. Insisto que na saúde temos especificidades, é parte do setor social, mas o mais importante é que o trabalho é muito diferenciado. O objeto tem em si gente....

\section{Como se deu o processo de concepção do Projeto Larga Escala?}

Sempre fui muito criativa. Sempre trabalhei com formação e treinamento de pessoal e vi que, a depender da forma como trabalhava, cada vez eles [os alunos] participavam mais. Eu experimentava, ficava vendo o que resultava. A maior dificuldade do processo ensino-aprendizagem com os alunos é conseguir fazer com que eles façam relações entre os conhecimentos. Se o aluno não estabelece relações, o ensino é decoreba, no fundo ele não aprendeu. Por exemplo, o aluno aprendia micro-organismos, mas não associava isto com a questão da infecção hospitalar. Era como se a infecção fosse outra coisa.

Comecei a perceber que a dissociação era alta. Então, estava disposta a mudar a situação. As pessoas tinham que dispor de um modo de aprender que mudasse e auxiliasse sua prática. Aí realmente compreendi que a formação, com todos os princípios articulados e a compreensão das causas dos fenômenos, seria muito importante para as pessoas e serviços. Fiz muitas coisas para articular teoria e pratica, conhecimento e funcionamento real das coisas. Busquei outros profissionais no próprio serviço para tentar fechar um ciclo de compreensão. Mais tarde, busquei sim, muito depois, compreender esse processo do ponto de vista mais geral. Mas antes experimentei muita coisa e percebi todas as dificuldades. Algumas coisas tentei e deram certo. Então, fui buscar compreender isso de uma forma que pudesse ser sistematizada e passada para outras pessoas que lidavam com os processo de formação.

Todo esse esforço redundou no Currículo Integrado e no uso da problematização. Quem começou com isso foi Hortência Holanda, com a educação e a saúde. Ela que me ensinou a problematizar. Eu não fiz mergulhos teóricos, porque nunca fui da teoria. Anos mais tarde, as pes- 
soas estudando o que havia ocorrido na saúde, elaborando suas teses, vieram me dizer das escolas, dos autores e de como isso poderia ter influenciado a construção da proposta. Bom, não tive essas influências teóricas para elaborar minhas propostas e desenvolver os cursos. Eu não sou teórica.

\section{Qual o saldo mais positivo da elaboração e do uso dos Currículos Integrados?}

Queria mostrar que não era a educação geral a responsável pela cidadania, mas sim as escolhas que os indivíduos fazem diante de opções. Quem faz e aplica a metodologia da problematização sabe disso. O indivíduo aprende a pensar, a refletir, a escolher.

\section{Qual sua opinião frente à perspectiva de alguns au- tores que questionam o processo ensino-aprendi- zagem na perspectiva da integração ensino-servi- ço, tomando por referência a discussão do trabalho como fonte de alienação?}

Pois é, se diz que o trabalho empobrece... O trabalho é riquíssimo, se você for pensar nele como processo de transformação. Na problematização, o que se busca é trazer o trabalho para o nível crítico, o indivíduo é desafiado. Isto só é possível se há domínio do objeto, do campo. Não estou falando do trabalho em tese. É preciso saber em profundidade do processo de trabalho real e do que ali ocorre. O trabalho por definição é um processo de transformação, não pode ser visto como empecilho à formação. Discordo dessa leitura que o serviço e a prática real são alienantes e, portanto, não fornecem os insumos adequados à formação. Pense bem...como formar os especialistas, os técnicos? Imagine...cadê a pobreza? Possibilita e cria ciência, isso sim! Tudo que aprendi na vida foi no trabalho.

\section{O que ocorreu de inovador nos últimos anos em termos de Educação Profissional?}

A experiência do Sistema de Certificação de Competências (SCC), desenvolvida pelo Profae [Projeto de Profissionalização dos Trabalhadores da Área de Enfermagem], foi muito boa e conti- nua sendo muito interessante pensar nesse tema. A certificação de competência, tal como foi pensada no Projeto, mantém um processo de regulação profissional mais societário, mais democrático, porque implica em um debate nacional. Afinal, não tem escola isolada que discuta isso e consiga se orientar para as necessidades. Isso deveria ser feito com todas as profissões! Terminou que o processo do Profae (metodológico) está influindo, como já sendo feito para o agente comunitário de saúde e para o técnico de enfermagem. O tema das competências na saúde vem sendo discutido de forma muito diferente de outros setores. O perfil de ação foi o ponto de partida, mas a discussão central é a definição dos eixos temáticos que expressam um conjunto de habilidades. Partindo do fazer, se buscou um eixo e, a cada eixo, foi adstrita uma competência.

As habilidades são uma forma de avaliar as competências. A competência vista de forma integral em suas três dimensões (conhecimento, saber fazer e saber ser), por isso a expressão da competência em saúde não pode ser fragmentada. Não se trata de fazer lista com fazeres, ela é muito mais complexa.

\section{Porque você considera o SCC tão importante?}

Porque, se tomado em toda sua inteireza, ou como foi pensado, ele se transforma em um processo de regulação. Isto é fundamental para o setor saúde. A regulação das corporações, por meio dos conselhos, não é suficiente ou satisfatória para o tema da Educação Profissional. A Regulação que, de fato, pode ser entendida como um campo de articulação entre saúde e educação. A escola faria o currículo com base em competências que foram legitimadas socialmente por um conjunto amplo de atores sociais. Acho isso uma questão da maior importância, que pode contribuir para elevar a qualidade da Educação Profissional das escolas e dos serviços de saúde.

Para você, hoje, qual o maior desafio ou lacuna que persiste no campo da Educação Profissional de nível técnico?

A questão da avaliação educacional é muito frágil, porque é um campo que foi abandonado, 
pouco aprofundado. Até porque requer especialização. O desafio maior é como captar o subjetivo. A avaliação de processo pode captar algo, mas como captar valores... Na avaliação formativa, dá para fazer, mas, na avaliação de competências, acho que não. Ainda não tenho uma conclusão sobre isso, mas é fundamental ir além das tradicionais avaliações.

\section{Como a Escola Politécnica de Saúde Joaquim Ve- nâncio pode contribuir para a consolidação da Educação Profissional de nível técnico em saúde?}

Sempre acreditei que, se não houver uma organização, uma instituição para pensar um campo, ele não se desenvolve. Muitos achavam que a ENSP cumpriria esse papel. Dei o maior apoio ao Luiz Fernando para a criação da Escola Politécnica de Saúde Joaquim Venâncio, apesar das divergências entre grupos e das dificuldades. Em meados dos anos 90, resgatei minha relação com a Escola na gestão da Tânia Celeste. Foi quando a OPAS, junto com a Fiocruz, desenvolveu o Projeto Escola. Na minha cabeça, o Poli era a única estrutura importante para assumir a liderança do processo de consolidação da Educação Profissional para o SUS. Hoje, continuo defendendo isso, apesar de ele ser diferente em relação às outras ETSUS. Ele tem uma estrutura que favorece ao crescimento de lideranças nessa área, e também a experimentação de modelos pedagógicos, de metodologias, além de apoio à Rede de Escolas Técnicas.

\section{Quais questões mereceriam maior ênfase na Edu- cação Profissional em saúde?}

Melhorar as condições das Escolas do SUS do ponto de vista metodológico, mas também tecnológico. A questão metodológica para articulação teoria-prática ainda precisa ser aprofundada, mas penso que fortalecer e desenvolver os Laboratórios de práticas é uma questão importante. O Programa de livro-texto precisa ser ampliado. O Poli começou, mas precisa avançar. É preciso preparar o docente não só do ponto de vista pedagógico, mas também técnico. Por exemplo, no caso da Promoção da Saúde, são muitas as rupturas que precisam ser feitas para que o docente consiga trabalhar nessa perspec- tiva e para que o tema ultrapasse o ideário nosso do setor.

\section{O que você pensa dos processos de educação a dis- tancia?}

Educação a distancia? Por princípio, não acredito em educação a distancia. A pessoa no máximo se informa, mas não incorpora, então não é educação. As pessoas têm que aprender a olhar, discriminar, pensar, refletir. Para alguém autodidata, de nível superior, com formação consolidada talvez, mas para nosso campo da educação profissional para a formação de técnicos, acho impossível. É olho no olho mesmo, dúvida na dúvida, são muitas transformações a serem feitas e o acompanhamento individual de cada um frente a frente é muito importante. Isso também inviabiliza completamente o que acredito de integração teoria-prática para essa formação.

\section{Qual sua avaliação desse momento em relação às políticas de Educação Profissional em saúde?}

Temo que, do jeito como as coisas estão indo, tenhamos a qualificação básica como modalidade que é aceita na saúde. Ora, como isso é possível? Isso é um retrocesso. Sou contra que os cursos da saúde possam ter terminalidade na qualificação básica. O risco de termos gente sem condições atendendo a população é alto demais. Combatemos tanto isso na saúde, utilizamos tantos recursos e, hoje, podemos vir a ter essa situação de volta. Já havíamos conseguido fazer o MEC entender que, em saúde, não é possível cursinhos de poucas horas.

Mostramos isso com o Auxiliar de Enfermagem. Brigamos para que fosse uma qualificação de nível técnico, justamente para ter coerência com as necessidades do setor saúde. Não é aceitável cursinho de 300 horas ou coisa parecida formando gente que será absorvida pelo setor para cuidar de gente. Isso realmente me entristece. Veja, se esse precedente é aberto, já sabemos onde vai dar isso. Os gestores e administradores vão contratar esses, os que geram mais supostamente mais economia e "valem menos" no mercado de trabalho. Teremos, de novo, milhares de pessoas sem formação. Hoje 2/3 dos trabalhadores estão excluídos, qual a política de 
formação para eles? Se nós acordamos que a qualificação básica é suficiente, estamos nos conformando com a situação atual e contribuindo para aprofundar a desigualdade.

\section{O que exatamente você considera um retrocesso?}

O silêncio do setor frente ao problema da formação dos trabalhadores de nível médio é meu maior desgosto. Acho que isto vem de novo predominando. Mesmo aqueles que se colocam na vanguarda do discurso sobre formação ainda têm propostas muito restritas, centradas quase sempre na educação médica, quando muito no nível superior. Jamais imaginei isso num contexto político como o que vivemos hoje. Parece que os processos de 20 anos que lutamos tanto estão sendo jogados fora. A Educação Profissional ser discutida a partir de uma escola da educação geral é um equívoco. A Educação Profissional como um apêndice é lamentável. A Educação Profissional tem rigor tecnológico. Isso eu tinha vontade de discutir com o Frigotto [Gaudêncio Frigotto], não em uma mesa redonda, com 40 minutos e sim num processo mais profundo, onde pudéssemos, inclusive, ir aos serviços de saúde, ver como as coisas acontecem.

Qual sua mensagem para quem hoje está chegando na área de educação, especialmente para trabaIhar com a formação de técnicos?

É preciso continuar, porque muita coisa pode e deve ser feita, mas é preciso que as pessoas tenham curiosidade e ousadia de experimentar e, acima de tudo, se perguntar porque tal ou qual escolha, porque utilizar essa ou aquela metodologia, ou ainda, quem e como pode ser beneficiado. Não existem pessoas incapazes de aprender, existem equívocos na utilização de determinadas propostas. 